\title{
A produção científica sobre gestão urbana: análise bibliométrica de 2010 a 2017
}

Marcus-Vinicius Gonçalves da Silva. Pontifícia Universidade Católica do Paraná, Curitiba, Brasil.

Mário Procopiuck. Pontifícia Universidade Católica do Paraná, Curitiba, Brasil.

RESUMO | A complexidade conceitual e epistemológica no campo de estudo da gestão urbana e sua característica dinâmica de adaptação a cada contexto, tem tornado cada vez mais difícil tanto a sua mensuração quanto o seu desempenho. Diante desse fato, utilizando-se da metodologia de caráter bibliométrico, esse trabalho tem o objetivo de mapear o terreno da produção intelectual sobre a gestáo urbana e de se conhecer a produção precedente. Como resultado, foi possível identificar que a produção científica na área de gestão urbana se constitui um campo de gradativo crescimento nos últimos anos e, que os periódicos melhores avaliados e os autores mais citados, respectivamente, podem auxiliar a fundamentação e sustentação teórica de pesquisas futuras, a fim de incrementar o relevante campo do conhecimento da gestão urbana.

PALAVRAS CHAVE | gestão urbana, teoria urbana, sociedade do conhecimento.

ABSTRACT | The conceptual and epistemological complexity in the field of study of urban management and its dynamic characteristic of adaptation to each context, has made it increasingly difficult both to measure and to perform. Given this fact, using the methodology of bibliometric character, this work has the objective of mapping the terrain of intellectual production on urban management and to know the previous production. As a result, it was possible to identify that scientific production in the area of urban management is a field of gradual growth in the last years and, that the best evaluated and most cited journals and authors, respectively, can support the theoretical foundation and support of future research, in order to increase the relevant field of knowledge of urban management.

KEYwORDs | urban management, urban theory, knowledge society. 


\section{Introdução}

As raízes conceituais da gestão urbana partem de tentativas de reformas de governos locais e do gerencialismo urbano na década de 1970. Desde meados da década de 1980, essa área de conhecimento assumiu uma abordagem mais institucional defendida pelas principais agências internacionais de fomento ao desenvolvimento (Davey, Batley, Devas, Norris \& Pasteur, 1996; Jenkins, 2000). Isso ocorria em meio a mudanças no quadro político-econômico da sociedade global, que reforçavam a importância da gestão urbana em um contexto de reestruturação dos modos de produção. Figurava-se, portanto, um momento histórico marcado por preocupaçóes com as crises do Estado decorrentes da ascensão do neoliberalismo, tendo como reflexos uma onda de descentralizaçáo e do acirramento competitividade entre as cidades (Werna, 1995).

Era um contexto com tendências de transferência de competências decisórias do nível nacional para o local, para tornar as cidades mais autônomas e, assim, capazes de conceberem e implementarem suas próprias estratégias de desenvolvimento. As cidades, nessa linha, passariam a se tornar "motores de crescimento", com a atração de investidores e mão de obra altamente especializada (Hall, 1993). O desafio, portanto, era compreender a natureza dos problemas urbanos frente à dinâmica da mudança do gerencialismo para o empreendedorismo (Harvey, 1989), pois até então, a gestão urbana se limitava ao planejamento dos aspectos físicos e territoriais da cidade e tinha como finalidade tratar da infraestrutura básica e da viabilizaçáo de serviços sociais.

Nos limiares do século corrente, o campo do conhecimento da gestão urbana já tinha ampliado o seu escopo para abranger variáveis de ordem social, política e econômica articuladas por diferentes atores públicos, privados e da sociedade civil local. Nessa linha, entraram na agenda da gestão urbana as transformaçóes fundamentais para viabilizar novos caminhos para a gestáo pública das cidades na, entáo emergente, sociedade da informaçáo (Frey, 2002), o que passou a exigir modelos inovadores, assim como novos instrumentos, recursos tecnológicos, procedimentos e formas de ação para criar condiçôes favoráveis de suporte às atividades locais e territoriais de agentes públicos e privados frente à globalização.

Era um momento em que o contexto local gerava complexidade crescente nos processos decisórios e ampliava a agenda urbana com temas relevantes, como, por exemplo, a geração de emprego, o desenvolvimento econômico local, a segurança pública, a poluição e o meio ambiente. Essas novas demandas revelavam certa incapacidade das instituiçóes políticas e administrativas locais tradicionais, normalmente vistas como aparatos de administração pública, para atuar e gerir com maior independência e autonomia em relação a outros atores para tornar as políticas públicas locais mais efetivas (Frey, 2003).

A partir dessa perspectiva, procuramos realizar o mapeamento do campo de produçáo intelectual sobre a área de gestáo urbana no contexto de publicaçóes nacionais e internacionais, com foco para a produção brasileira. A investigação se pautou em uma bibliometria para identificar as tendências de tal área do conhecimento a 
partir de autores, instituições e periódicos mais relevantes no campo de pesquisas sobre gestão urbana.

De início, para dar continuidade à trajetória desenvolvida até este ponto, na próxima seção é realizada a contextualização teórico-conceitual sobre cidade e gestão urbana para, em seguida, traçarmos o percurso metodológico da pesquisa e, finalmente, apresentarmos os resultados e discussóes que levarâo às conclusóes.

\section{Cidade e gestão urbana no contexto global}

As teorias e políticas internacionais sobre desenvolvimento urbano vêm passando por profundas mudanças ao longo das últimas décadas, principalmente como reflexos da guinada de interpretaçóes sobre questóes urbanas a partir dos anos 1960 (Monte-Mór, 2006). Com escopo na transformação e função das cidades, as teorias sobre desenvolvimento mediado pelo planejamento e gestão assumiram relevância para compreender as intervençóes do Estado e seus reflexos na sociedade. Entretanto, parte dessas teorias desenvolvidas em países do centro capitalista tiveram dificuldades para serem apropriadas nas periferias e, em muitos casos, se representaram com "ideias fora do lugar" colocando parte das cidades como "lugares fora das ideias" (Maricato, 2000).

No início dos anos 1970, a crise fiscal do Estado se anunciava nas cidades, projetando as bases para a redefiniçấo do papel do Estado na década seguinte (Castells, 1989). A cidade da prosperidade, do progresso e do desenvolvimento começava a ser apropriada como a cidade do capital globalizado (Monte-Mór, 2006). No mundo dos estudos urbanos, críticas sobre a cidade a partir da economia política começaram a assumir relevância, formando uma escola de pensamento sobre questão urbana e regional.

Nesses estudos, David Harvey (1975) e Manuel Castells (1977) assumem o protagonismo nos estudos urbanos e regionais com formulaçóes críticas de cunho marxista (Monte-Mór, 2006). Enquanto isso, a produção do espaço urbano e regional no Brasil ocorria com a estruturação de forças socioculturais, econômicas e políticas entre campo e cidades. As construçôes teóricas, partindo das cidades coloniais até a realidade das metrópoles, passaram a ser redefinidas, adaptadas e recriadas para explicar processos socioespaciais e informar projetos políticos de classes e de grupos de interesse que se articulavam dentro e fora do Estado (Maricato, 2000).

Nesses esforços iniciais, os conceitos teóricos de gestáo urbana tenderam a se manter multifacetados (Hirst, 2000; Rhodes, 2000). Não obstante, esses esforços contribuíram para que ocorressem mudanças substanciais tanto na área da política urbana quanto dos estudos urbanos independentemente da existência de um conjunto coeso de teorias formadas a partir da transformação dos tradicionais princípios da autoridade estatal.

A gestão urbana passou, com isso, a assimilar novas tendências sobre uma gestáo compartilhada e interinstitucional para abarcar tanto o setor público quanto o setor produtivo (Frey, 2004). Longe de ser questão resolvida, atualmente observa-se o desenvolvimento socioespacial urbano desigual associado com a proliferação de demandas de escalas nacionais e globais, impondo que as abordagens e métodos 
sobre gestão urbana se sujeitem as crescentes variaçóes para dar conta da diversidade empírica da cidade como um lugar.

Apesar de relativamente curta, a história do desenvolvimento da gestão urbana mostra tendências de um desenvolvimento teórico em um processo lento, flexível e sujeito a avaliaçóes permanentes. No campo da prática, à gestão urbana vêm sendo impostas condiçôes para que se mostre útil para otimizar a obtenção e aplicação de recursos, buscando o equilíbrio entre receitas e despesas, como ocorre em qualquer tipo de gestão. A diferença da gestão urbana, tanto no campo dos teóricos quanto dos praticantes, está nas dificuldades que enfrenta por não atuar a partir de um centro claramente definido de poder, mas a partir da conjunção de aspiraçóes de uma miríade de atores locais, regionais, nacionais e internacionais.

A trajetória da gestão urbana revela a importância de que seja discutida tanto sobre o papel da ciência básica que lhe dá gênese quanto aos aspectos de ciência aplicada, dedicada a contribuir para mitigar os contrastes e dificuldades enfrentadas no contexto urbano relacionado do contexto sociopolítico local ao global.

Situada no campo mais amplo dos estudos urbanos, a gestáo urbana se alinha a uma linha de pesquisa que, na proposta por Wachsmut (2013), questiona o papel da cidade apontando para a reorientaçáo dos empreendimentos teóricos para procurar explicar (i) os processos de estruturação e a transformação dos espaços urbanos através de novas categorias de análise; e, (ii) as formas pelas quais esses espaços se relacionam com a vida e a reprodução das relaçóes sociais de poder de forma prática.

\section{Percurso metodológico}

O estudo se pauta no método bibliométrico, tendo natureza exploratória e abordagem qualitativa, com recorte temporal longitudinal. Os dados foram obtidos em artigos disponíveis sobre a gestão urbana na base de dados Scopus, entre 2010 e outubro de 2017. A Scopus é considerada o maior banco de informaçóes multidisciplinar, formado por resumos e citaçóes de literatura revisada por pares, que é utilizado por cerca de 3.000 instituiçóes acadêmicas, governamentais e corporativas (Elsevier, 2017).

A estratégia para obtenção dos dados e informaçôes partiu da (i) seleção de um portfólio bibliográfico relevante sobre a gestão urbana e avançou para (ii) a análise bibliométrica para identificar periódicos, artigos, autores e palavras-chave de destaque. Essas informaçóes foram extraídas a partir de métricas de desempenho de 239 países de um universo de mais de 21.500 títulos frutos do trabalho de mais de 5.000 editores internacionais (sJR, 2017).

Os indicadores bibliométricos foram obtidos para gerar um conjunto coerente de informaçôes sistematizáveis para formar uma visão ampla do tema gestão urbana e, ao mesmo tempo, com sensibilidade para identificar lacunas e fragilidades.

Para isso, inicialmente, foi utilizada a expressão "Urban Management", entre aspas, para realizar a busca exata em artigos nacionais e internacionais. Em seguida, houve a seleção dos artigos para formar um portfólio bibliográfico de referência. De tal portfólio, passou-se para a apuração da relevância de periódicos, artigos, autores e palavras-chave. 


\section{Apresentação dos resultados e discussáo}

Nas quatro etapas a seguir, a análise dos resultados passará pela descrição dos resultados decorrentes da coleta dos dados e pela filtragem de periódicos mais representativos de estudos sobre gestão urbana.

\section{Primeira etapa da pesquisa}

A coleta dos artigos foi (i) pautada pela adequação do conteúdo da base ao tema de pesquisa, (ii) quantidade de artigos disponíveis e, (iii) pelo levantamento dos autores e periódicos de maior relevância nacional na área da gestão urbana. Como resultado inicial, foram localizados 430 artigos, com distribuição temporal e quantitativa mostrada na figura 1 .

\section{Figura I | Publicaçôes (2010-2017)}

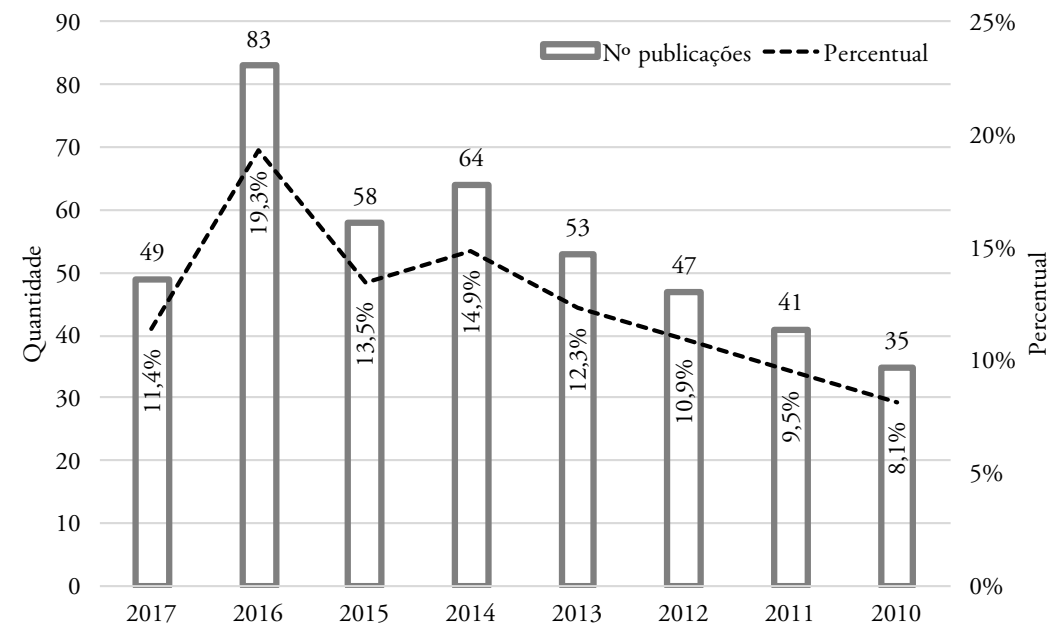

FONTE SCOPUS

A distribuição temporal apresentada na figura 1 mostra uma trajetória ascendente de 2010 até 2016, com uma redução acentuada em 2017. Uma possível explicação para tal reduçáo é que os dados foram coletados somente até outubro de 2017.

O periódico com o maior número de publicaçóes entre 2010 e 2017 foi o Theoretical And Empirical Researches In Urban Management (TERUM), da Romênia, com 12 publicaçóes na área de gestão urbana. Seu escopo abarca análises teóricas e empíricas multidisciplinares sobre questôes sociais, econômicas e técnicas relacionadas ao desenvolvimento e gerenciamento urbano. Dentre os tópicos relacionados à gestão urbana, destacam-se planejamento urbano, desenvolvimento urbano, design urbano, políticas urbanas, gestão de infraestrutura urbana, políticas ambientais municipais, gestáo sustentável urbana, transporte urbano, modelagem urbana.

O periódico romeno TERUM foi fundado pelo Research Centre in Public Administration and Public Services, da Academy of Economic Studies, de Bucharest, 
na Romania, em novembro de 2006. Atualmente, é classificado no estrato B2 do Qualis/Capes, ${ }^{1}$ e Q3 no SCImago Journal Rank (sJR). ${ }^{2}$ A posição em nível secundário nos estratos dessas duas bases de avaliação de periódicos pode ser explicada pelo curto tempo de vida da revista, pois a elevaçáo para estratos superiores depende de citaçóes em outros periódicos bem classificados ao longo do tempo.

$\mathrm{Na}$ figura 2 são apresentados os periódicos nacionais e internacionais disponibilizados na base Scopus, com o número de publicaçôes maior que cinco, relacionadas ao tema gestão urbana.

\section{FIGURA 2 Periódicos nacionais e internacionais com mais de cinco publicaçóes}



FONTE SCOPUS

Dentre os 110 artigos publicados nos periódicos relacionados na figura 2, no âmbito nacional, a Revista Brasileira de Gestão Urbana (URBE), do Programa de Pós-Graduação em Gestão Urbana, da Pontifícia Universidade Católica do Paraná (PPGTU/PUCPR), se destaca no quinto grupo mais bem posicionado, com sete publicaçóes $(6,4 \%)$.

A figura 3 mostra a distribuição das 554 palavras-chave mais citadas na área de gestấo urbana nas temáticas com mais de 20 citaçôes.

No rol das palavras-chaves da figura 3, destacam-se os termos 'Urban Management', 'Urban Planning' e 'Urban Development', utilizados 137, 105 e 60 vezes, respectivamente.

1 O Qualis é um sistema da Plataforma Sucupira da Coordenação de Aperfeiçoamento de Pessoal de Nível Superior (CAPES) utilizado para classificar os periódicos científicos. A classificação é realizada pelos comitês consultores de cada área de avaliação seguindo critérios previamente definidos em termos de importância relativa de periódicos para cada área a que se vinculam programas de pósgraduação no Brasil.

2 O sJR avalia periódicos a partir das informaçóes contidas na base de dados Scopus . 
FIGURA 3 | Keywords mais utilizadas nos artigos (2010-2017)

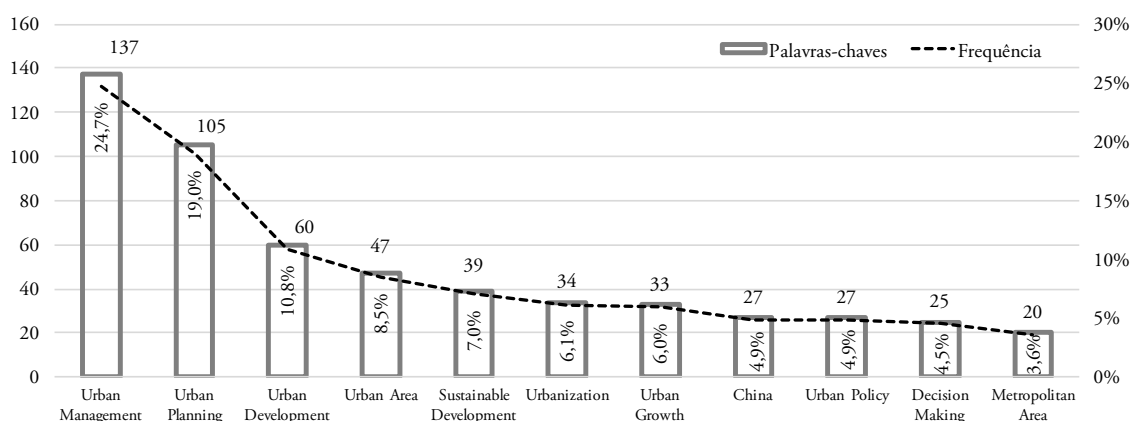

FONTE SCOPUS

A figura 4 ilustra a distribuição das 220 publicaçóes em função dos países de origem dos seus autores.

FIGURA 4 | Publicações por país (2010-2017)

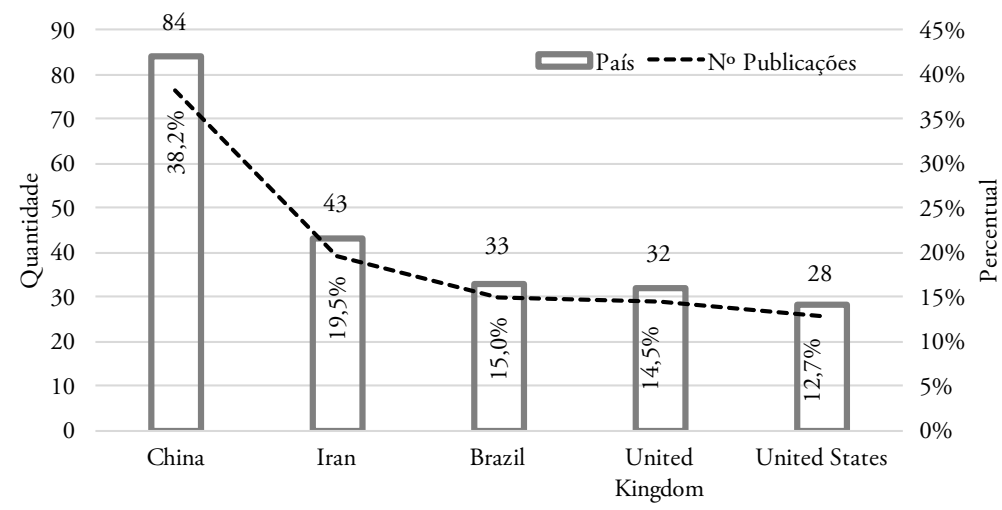

FONTE SCOPUS

A figura 4 mostra que a principais relaçóes de coautoria ocorrem entre pesquisadores filiados a instituiçôes chinesas, seguidas das iranianas e brasileiras. Dos cinco países com maior número de parcerias em pesquisa, dois são asiáticos, um norte-americano, um europeu e um sul americano, com destaque para o número de publicaçóes nos países asiáticos, China e Iran.

No universo das 554 publicações em grandes áreas do conhecimento (figura 5), 227 (42,5\%) relacionam-se a área de Ciências Sociais (Social Sciences), sendo $89 \%$ internacionais e $11 \%$ de brasileiras. Das 128 publicaçóes da área de Ciências Ambientais (Environmental Science), 5\% são nacionais e, da área de Engenharia, $10,4 \%$ são nacionais. 
FIGURA 5 Grandes áreas do conhecimento

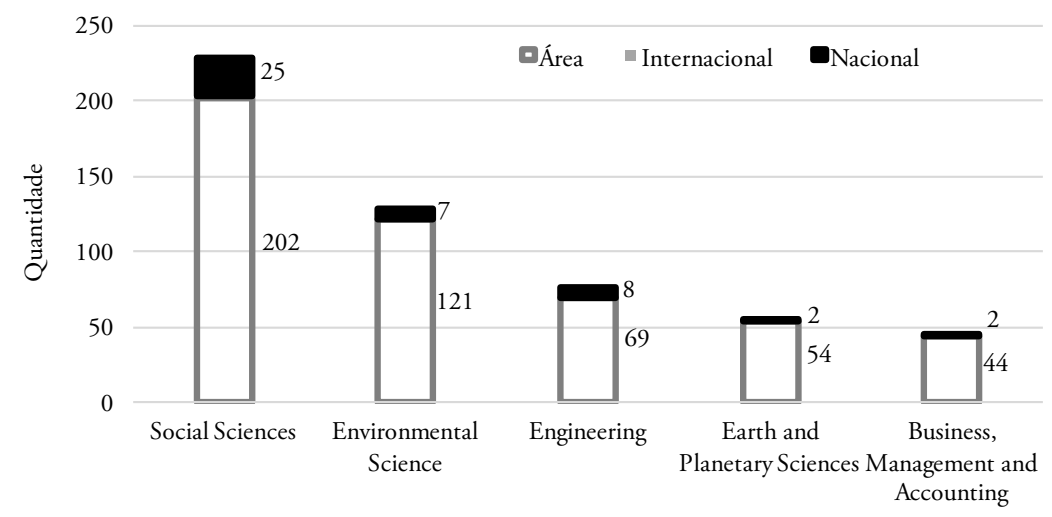

FONTE SCOPUS

Se, por um lado, a área Ciências da Terra e Planetárias, com 54 artigos, e a área de Negócios, Gestão e Contabilidade, com 44 artigos, se destacam em termos de publicaçôes internacionais, por outro, há uma baixa participação nas publicaçôes nacionais. Apesar desse desequilíbrio, de forma geral, os dados da figura 5 mostram que há diversidade do campo de estudo da gestão urbana e interação com outras áreas do conhecimento.

\section{Segunda etapa da pesquisa}

Nesta etapa, a filtragem dos periódicos teve como critério que contivessem, no mínimo, um artigo publicado, do que totalizou 21 revistas, conforme distribuiçáo mostrada na figura 6 .

FIGURa 6 | Publicaçóes por periódicos (2010-2017)

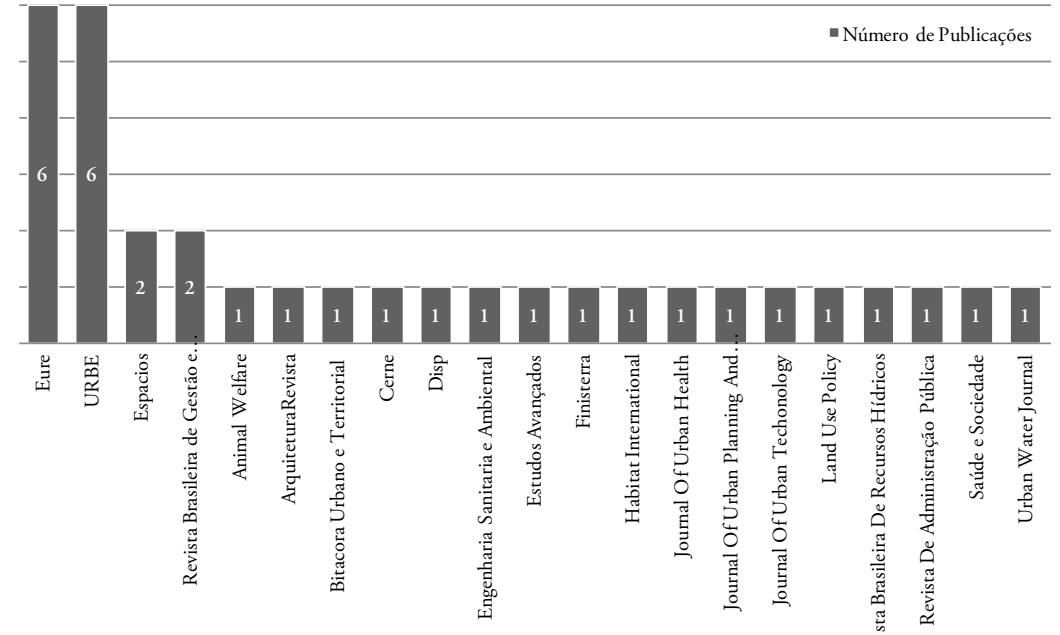

FONTE SCOPUS 
Observa-se na figura 6, que as revistas com o maior número de artigos publicados são a Eure, Revista Brasileira de Gestão Urbana (URBE), Espacios e Revista Brasileira de Gestão e Desenvolvimento Regional. As demais revistas nacionais, Animal Welfare, ArquiteturaRevista, Bitacora Urbano Territorial, Cerne, Disp - The Planning Review, Engenharia Sanitária e Ambiental, Estudos Avançados, Finisterra, Habitat International, Journal of Urban Health, Journal of Urban Planning and Development, Journal of Urban Technology, Land Use Policy, Revista Brasileira de Recursos Hidricos, Revista de Administração Pública, Saúde e Sociedade e Urban Water Journal. Esses periódicos correspondem a $43 \%$ da publicação total.

$\mathrm{Na}$ tabela 1 constam os periódicos analisados, com as respectivas classificaçóes no ranking Qualis da área de Planejamento Urbano e Regional/Demografia e índice Scimago Journal \& Country Ranking.

TABELA I | Classificação de periódico pelos indicadores Qualis e sJR

\begin{tabular}{|c|c|c|c|c|}
\hline PERIÓDICO & PAÍS & QUALIS & SJR & H INDEX \\
\hline EURE & Chile & AI & $\mathrm{Q} 2$ & I7 \\
\hline Habitat International & Reino Unido & AI & QI & 47 \\
\hline Journal of Urban Health & Estados Unidos & AI & QI & 73 \\
\hline Journal of Urban Planning and Development & Estados Unidos & AI & $\mathrm{Q} 2^{2}$ & $3 \mathrm{I}$ \\
\hline Journal of Urban Technology & Reino Unido & AI & QI & 25 \\
\hline Land Use Policy & Holanda & AI & $\mathrm{QI}$ & 77 \\
\hline Urban Water Journal & Reino Unido & AI & QI & 25 \\
\hline ArquiteturaRevista & Brasil & A2 & Q3 & 3 \\
\hline Bitacora Urbano Territorial & Colômbia & A2 & Q4 & 2 \\
\hline Cerne & Brasil & A2 & Q2 & 12 \\
\hline Disp - The Planning Review & Reino Unido & A2 & Q3 & 15 \\
\hline Engenharia Sanitária e Ambiental & Brasil & A2 & Q4 & II \\
\hline Estudos Avançados & Brasil & A2 & $\mathrm{Q} 2$ & I5 \\
\hline Revista Brasileira de Gestão e Desenvolvimento Regional & Brasil & A2 & Q3 & 3 \\
\hline Revista de Administração Pública & Brasil & A2 & Q3 & II \\
\hline Saúde e Sociedade & Brasil & A2 & Q2 & I3 \\
\hline URBE & Brasil & A2 & Q3 & I \\
\hline Animal Welfare & Reino Unido & B I & QI & 50 \\
\hline Revista Brasileira de Recursos Hídricos & Brasil & B I & - & - \\
\hline
\end{tabular}

FONTE PLATAFORMA SUCUPIRA E SJR (20I7)

Dos 19 periódicos mais importantes para a área de Gestão Urbana, 17 possuem avaliação "A” no Qualis/CApes, e estáo indexados na base de dados Scopus . A revista Animal Welfare apresenta um alto índice no sJR com QI, H Index 50, e Qualis BI. Já a Revista Brasileira de Recursos Hidricos possui Qualis B I, mas não possui índice SJR. Cabe ressaltar que compete à Comissão de Avaliaçáo da CAPEs, estabelecer os critérios de avaliação dos periódicos das respectivas áreas. 


\section{Terceira etapa da pesquisa}

Nesta terceira e última etapa da pesquisa, houve a identificação dos autores e periódicos brasileiros que se mostraram mais relevantes neste estudo, especificamente, sobre a gestão urbana no Brasil: Mario Procopiuck (PUCPR), Alberto de Oliveira (UfRJ), Pedro Roberto Jacobi (USP) e Klaus Frey (UfABC), cada um com duas publicaçôes, indexadas na base de dados Scopus.

$\mathrm{O}$ artigo "Megaevents, urban management, and macroeconomic policy", publicado no Journal of Urban Planning and Development (De Oliveira, 2011), trata do crescimento de megaeventos relacionado às mudanças de concepçóes sobre a gestão urbana e aborda as relaçóes entre a hospedagem dos jogos pan-americanos de 2007, a gestão do orçamento daquela cidade e a política macroeconômica do Brasil. O segundo artigo do autor, publicado na EURE, em 2013, intitulado "Large urban projects as a strategy for economic growth" (De Oliveira, 2011), trata de experiências de Sáo Paulo e Rio de Janeiro em relaçáo aos limites, custos e potencial de grandes projetos urbanos.

No trabalho de Procopiuck, “'Evaluation of communities': perception on public policies, urban rivers functions, and qualities", publicado no Urban Water Journal (Procopiuck \& Rosa, 2015), busca-se apreender a percepçáo das comunidades locais sobre açóes sociopolíticas e os atributos naturais de um rio urbano curitibano. $\mathrm{O}$ segundo, intitulado "Public Policy and a Strategic Digital City Project", publicado no Journal of Urban Technology (Procopiuck, Rezende \& Figueiredo, 2015) traz uma visão geral das discussóes globais sobre cidades digitais e de suas relaçóes com políticas públicas, descrevendo e analisando o planejamento da informação municipal a partir de um projeto implementado no município de Vinhedo, em Sáo Paulo. $\mathrm{O}$ estudo enfatiza a importância da adoção de uma metodologia de projeto para implementação coletiva para elevar a eficiência, com base no conceito estratégico da cidade digital.

No trabalho de Jacobi, "Urban Environmental Management and Governance”, publicado na DISP (Jacobi \& Peres, 2016), o foco se volta para o crescimento das áreas metropolitanas brasileiras nas últimas décadas, onde atualmente se concentram $84 \%$ da população, das dificuldades da gestão urbana para mitigar problemas de inundaçóes, saneamento e gerenciamento de resíduos sólidos. Os desafios apontados são na integração intergovernamental e a criação de espaços inovadores para dialogar com os diversos setores da sociedade especialmente sobre questóes socioambientais. O segundo, intitualdo "Action and reaction: urban interventions and the performance of institutions in post-disaster blumenau (Brazil)", publicado na EURE (Jacobi, Momm-Schult \& Bohn, 2013) trata do desastre ocorrido em 2008 no Vale do Rio Itajaí-Açu, na região sul do Brasil. A atenção se volta para os efeitos na área urbana da cidade catarinense de Blumenau, com foco no planejamento territorial pós-desastre e do desempenho institucional na gestáo de recursos naturais. $\mathrm{O}$ caso evidenciou que as intervençóes naquela situação de exceção e emergências por um sistema frágil de governança resultou em conflitos entre a administração municipal, as instituiçóes e atores organizados em torno da proteção ambiental e dos recursos hídricos. 
O trabalho de Frey, "The city and the sociopolitical construction of urban-technological planning”, publicado na EURE (Firmino \& Frey, 2014) chama a atenção para utilização crescente das Tecnologias de Informação e Comunicação (TIC) no planejamento e gestão urbana. A conclusão é que, embora o processo de construção sociopolítica de tecnologias urbanas siga uma lógica setorial e fragmentada, é premente que se avance para estratégias urbanas integradas. O segundo, intitulado "Management practices of urban mega projects", publicado na Revista Saúde e Sociedade (Frey, Gadens \& Hardt, 2012) trata-se de pesquisa bibliográfica sobre a formação e implementação dos Mega Projetos Urbanos no Brasil desde a década de 1970, estabelecendo relaçóes com as práticas e modelos de gestão até a atualidade.

As palavras-chaves utilizadas com maior frequência nos artigos acima são: Urban Management $(n=6)$, Digital City $(n=3)$, Public Policies $(n=3)$, Urban Development $(n=2)$, Government Policies $(n=2)$, Environmental Management $(n=2)$, conforme ilustrado na figura 7.

FIGURA 7 Keywords mais utilizadas nos artigos de autoria nacional

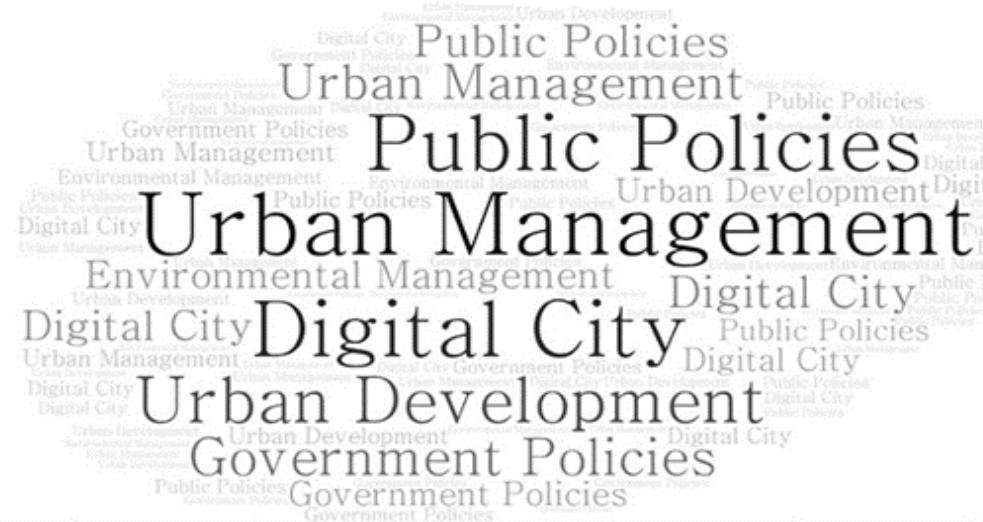

FONTE ELABORAÇÃo PRÓPRIA

Como visto acima, as discussóes das questôes relacionadas com a gestão urbana aparecem mais como um elemento contextual para delimitar as unidades de análise de temáticas que ocorrem nas cidades, sujeitas à interferência de agentes com capacidade decisória.

\section{Análise do portfólio bibliográfico}

Nesta etapa, faz-se uma delimitação do portfólio bibliográfico com os periódicos nacionais situados no estrato "A" do Qualis/Capes e com, pelo menos, uma citação na base de dados Scopus, aqueles periódicos nacionais e autores mais relevantes sobre gestão urbana (tabela 2). 
TABEla 2 Portfólio bibliográfico

\begin{tabular}{|l|l|l|l|c|}
\hline \multicolumn{1}{|c|}{ AUTORES } & \multicolumn{1}{|c|}{ TítUlo } & ANO & PERIódico & $\begin{array}{c}\text { CITAÇÓES No } \\
\text { SCOPUS (N) }\end{array}$ \\
\hline $\begin{array}{l}\text { Cardoso, S. L. C., } \\
\text { Vasconcellos Sobrinho, } \\
\text { M. \& Vasconcellos, A. } \\
\text { M. A. }\end{array}$ & $\begin{array}{l}\text { Environmental management of } \\
\text { urban parks: The case of the Gunnar } \\
\text { Vingren Ecological Park in Belem, } \\
\text { Para state, Brazil }\end{array}$ & 2015 & Urbe & 3 \\
\hline Wilheim, J. & $\begin{array}{l}\text { Mobilidade urbana: Um desafio } \\
\text { paulistano }\end{array}$ & 2013 & $\begin{array}{l}\text { Estudos } \\
\text { Avançados }\end{array}$ & 3 \\
\hline Braga, R. & $\begin{array}{l}\text { Regional dynamics and urban policy: } \\
\text { An analysis of medium sized cities of } \\
\text { administrative region of Campinas/sP }\end{array}$ & 2011 & G\&DR & 1 \\
\hline
\end{tabular}

FONTE SCOPUS

Como fase subsequente de construção do portfólio bibliográfico para o tema da pesquisa é realizada a análise dos artigos constantes da tabela 2 .

Os trabalhos foram publicados em três periódicos nacionais de elevada relevância para estudos da gestão urbana. A $U R B E$ tem publicação semestral e vincula-se ao Programa de Pós-Graduação em Gestão Urbana, da Pontifícia Universidade Católica do Paraná. É um fórum de discussão sobre questôes urbanas em geral e à gestão urbana em específico para divulgação científica de estudos teóricos e empíricos originais sobre questóes relacionadas à organização das cidades e regióes de diferentes contextos, com indexação nas bases de dados Scopus, DOAJ, Redalyc, e Latindex, e com H 5 index 7 na classificação do Google Scholar.

A revista Estudos Avançados é uma publicação quadrimestral multidisciplinar do Instituto de Estudos Avançados da usp, criada em 1987, que publica trabalhos sobre questóes de relevância nacional e internacional e visa transformar o conhecimento e a crítica em alavanca do progresso social, não só dos brasileiros como de todos os povos em desenvolvimento. A revista é indexada nas bases de dados Scopus, Scielo, Latindex, Lilacs e Ibict e tem classificaçáo Q2 no sJR.

A $G \mathscr{\mho} D R$ tem frequência quadrimestral, e se vincula ao programa de Pós-Graduação Stricto e Lato Sensu em Gestão e Desenvolvimento Regional, da Universidade de Taubaté (sP). Com orientação pluralista, publica trabalhos teóricos e empíricos sobre Desenvolvimento Regional, e está classificada no estrato A2 do Qualis e Q3 do SJR.

$\mathrm{O}$ artigo mais citado é o "Environmental management of urban parks: The case of the Gunnar Vingren Ecological Park in Belem, Para state, Brazil" (Cardoso, Vasconcellos Sobrinho \& Vasconcellos, 2015), com três citaçóes na base Scopus. A publicação da Revista Urbe se insere em discussão sobre os fatores relacionados à implantação de parques urbanos, como participação, governança urbana e gestáo ambiental. $\mathrm{O}$ artigo trata da importância dos movimentos sociais urbanos na preservação das áreas verdes da cidade e no melhoramento da qualidade da vida urbana, concluindo que o contexto de gestão urbana influencia o nível de participação dos atores sociais nos comitês de gestão dos parques.

Também com três citaçôes, o artigo "Mobilidade urbana: Um desafio paulistano", publicado em Estudos Avançados (Wilheim, 2013), avalia a mobilidade urbana com 
base nos fluxos de informaçóes, bens e de pessoas. A conclusão é que cabe às políticas públicas o planejamento urbano e a abertura de espaços para proposição de melhorias na gestão urbana visando à promoção de mudanças de padrốes de uso de automóveis, de sistematização dos modais de transporte, e de pontualidade e conforto no transporte.

O artigo de Braga (2011), "Regional dynamics and urban policy: An analysis of medium sized cities of administrative region of Campinas/sp", publicado na Revista Brasileira de Gestão e Desenvolvimento Regional, possui uma citação na base de dados Scopus, e visa avaliar a implantação de instrumentos de gestão urbana em cidades médias de São Paulo, com ênfase na Região Administrativa de Campinas. Os resultados apontam uma situação preocupante em razão da falta de correlação entre a implantaçáo de tais instrumentos e com o tamanho, crescimento e renda nas cidades médias.

Nesse conjunto de publicaçóes em revistas nacionais, diferente do que ocorre com publicaçôes de autores brasileiros em revistas internacionais, o foco tendeu a se voltar para dimensóes específicas da gestão urbana. A gestão urbana deixa, assim, de servir como contexto e passa a se posicionar como ferramenta para articular grandes questóes urbanas que, de alguma forma, demandam intervençóes planejadas e administradas.

\section{Consideraçóes finais}

O mapeamento do perfil da produção científica na área da gestão urbana em periódicos nacionais e internacionais indexados na base de dados Scopus, levou à construção de um portfólio com os artigos mais relevantes sobre tal tema, que, por meio de análise bibliométrica, permitiu avaliar a relevância de artigos, autores, periódicos e palavras-chave em publicaçóes ocorridas entre 2010-2017.

A investigação explicitou o estado atual dos estudos sobre o tema gestão urbana. Este referencial poderá contribuir para o aprofundamento do conhecimento do tema e, assim, contribuir para avançar na agenda de pesquisa e produção acadêmica sobre a gestão urbana no Brasil, abrindo espaços para novas análises e reflexôes sobre os rumos do planejamento e desenvolvimento urbano do país.

O trabalho mostrou que a produção científica na área de gestão urbana se encontra em estágio ainda embrionário, mas com tendências de elevado crescimento nos últimos anos. Não obstante o seu estágio inicial, esse campo de conhecimento já se mostra relevante em diferentes países, em investigaçôes que procuram compreender a gestão urbana em diferentes contextos e em discussóes de diferentes temáticas sobre as cidades. Ainda, a identificação de pesquisadores, periódicos e temas correlatos mais citados poderá auxiliar na revisão bibliográfica básica de futuras investigaçóes.

A tendência explicitada de crescimento expressivo da produção brasileira indexada nas bases de dados internacionais sobre gestão urbana está associada ao crescimento do número e da qualidade dos programas e alunos de pós-graduação na área de avaliação da Coordenação de Aperfeiçoamento de Pessoal de Nível Superior 
(CAPES), Planejamento Urbano e Regional/Demografia (pur/Demografia), bem como à elevação da maturidade e qualificação dos pesquisadores.

Finalmente, como recomendação para pesquisas futuras, há possibilidades de aprofundamento a partir de estudos comparativos com outras bases de dados, bem como com teses, dissertaçóes, livros e congressos científicos.

\section{Referências bibliográficas}

Braga, R. (2011). Dinâmica regional e política urbana: Uma análise das cidades de porte médio da região administrativa de Campinas/sp. Revista Brasileira de Gestão e Desenvolvimento Regional, 7(2), 3-24. http://www.rbgdr.net/revista/index.php/rbgdr/article/view/422

Cardoso, S. L. C., Vasconcellos Sobrinho, M. \& Vasconcellos, A. M. (2015). Gestáo ambiental de parques urbanos: o caso do Parque Ecológico do Município de Belém Gunnar Vingren. Revista Brasileira de Gestão Urbana, 7(1), 74-90. http://dx.doi. org/10.1590/2175-3369.007.001.AO05

Castells, M. (1977). The urban question: a Marxist approach. Cambridge, MA: MIT Press.

Castells, M. (1989). The informational city: information technology, economic restructuring, and the urban-regional process. Oxford: Blackwell.

Davey, K., Batley, R., Devas, N., Norris, M. \& Pasteur, D. (1996). Urban management: The challenge of Growth. Aldershot: Avebury.

De Oliveira, A. (2011). Megaevents, urban management, and macroeconomic policy: 2007 Pan American Games in Rio de Janeiro. Journal of Urban Planning and Development, 137(2). https://doi.org/10.1061/(ASCE)UP.1943-5444.0000054

De Oliveira, A. (2013). Os grandes projetos urbanos como estratégia de crescimento econômico. EURE, 39(117), 147-163. http://dx.doi.org/10.4067/S0250-71612013000200007

Elsevier (2017). Scopus. Disponível em: <https://www.elsevier.com/americalatina/pt-br/ scopus $>$. Acesso em: 16/11/2017

Frey, K. (2002). Governança eletrônica: experiências de cidades europeias e algumas liçóes para países em desenvolvimento. Em J. Eisenberg \& M. Cepik (orgs.), Internet e política: teoria e prática da democracia eletrônica (pp. 141-163). Belo Horizonte: Editora UfMG.

Frey, K. (2003). Governança urbana e redes sociais: o potencial das novas tecnologias da informação e comunicação. Em Encontro Anual da Anpad, 27, Atibaia. Anais... Atibaia: ANPAD.

Frey, K. (2004). Governança interativa: uma concepção para compreender a gestão pública participativa? Política \& Sociedade, (5), 117-136. Disponível em: <https://periodicos. ufsc.br/index.php/politica/article/view/1982>. Acesso em: 10/11/2017

Frey, K., Gadens, L. N. \& Hardt, L. P. A. (2012). Das práticas de gestão de grandes projetos urbanos. Saude e Sociedade, 21, 21-32.

Firmino, R. \& Frey, K. (2014). La ciudad y la construcción socio-política de la planificación urbano-tecnológico. EURE, 40(119), 99-118. http://www.eure.cl/index.php/eure/ article/view/347/605

Hall, P. (1993). Forces shaping urban Europe. Urban Studies, 30(6), 883-898. https://doi. org/10.1080\%2F00420989320080831 
Harvey, D. (1975). Social justice and the city. Londres: Edward Arnold.

Harvey, D. (1989). The urban experience. Oxford: Blackwell.

Hirst, P. (2000). Democracy and governance. Em J. Pierre (org.), Debating governance: authority, steering and democracy (pp. 13-35). Nova York: Oxford University Press.

Jacobi, P., Momm-Schult, S. \& Bohn, N. (2013). Ação e reação: Intervençóes urbanas e a atuação das instituições no pós-desastre em Blumenau (Brasil). EURE, 39(116), 243262. http://dx.doi.org/10.4067/S0250-71612013000100010

Jacobi, P. \& Peres, U. D. (2016). Urban environmental management and governance. DISP The Planning Review, 52(2), 26-34. https://doi.org/10.1080/02513625.2016.1195580

Jenkins, P. (2000). Urban management, urban poverty and urban governance: planning and land management in Maputo. Environment and Urbanization, 12(1), 137-152. https:// journals.sagepub.com/doi/pdf/10.1177/095624780001200110

Maricato, E. (2000). As ideias fora do lugar e o lugar fora das ideias. Em O. B. F. Arantes, C. B. Vainer \& E. Maricato (eds.), A cidade do pensamento único: desmanchando consensos (pp.121-192). Petrópolis: Vozes.

Monte-Mór, R. L. (2006). As teorias urbanas e o planejamento urbano no Brasil. Em C. C. Diniz \& M. Crocco (eds.), Economia Regional e Urbana: Contribuiçôes Teóricas Recentes (pp. 61-85). Belo Horizonte: UfMG.

Plataforma Sucupira. Qualis-Periódicos. (2017). Disponível em: <https://sucupira.capes.gov.br/ sucupira/public/index.xhtml>. Acesso em: 15/11/2017.

Procopiuck, M. \& Rosa, A. (2015). Evaluation of communities' perception on public policies, urban rivers functions, and qualities: the Belém River case in Curitiba. Urban Water Journal, 12(7), 597-605. https://doi.org/10.1080/1573062X.2015.1024690

Procopoiuk, M., Rezende, D. A. \& Figueiredo, F. C. (2015). Public policy and a strategic digital city project: A case study of the Brazilian Municipality Of Vinhedo. Journal of Urban Technology, 22(2), 63-83. https://doi.org/10.1080/10630732.2014.971536.

Rhodes, R. A. W. (2000). Governance and public administration. Em J. Pierre (ed.), Debating governance: authority, steering and democracy (pp. 54-90). Nova York: Oxford University Press.

SCIMago Journal \& Country Rank. (2017). sJR. Disponível em: <http://www.scimagojr.com/ aboutus.php>. Acesso em: 10/11/2017.

Wachsmuth, D. (2013). Teoría urbana sin ciudadismo metodológico. Urban, (6), 23-35. http://polired.upm.es/index.php/urban/article/view/2051/2098

Werna, E. (1995). The management of urban development, or the development of urban management? Problems and premises of an elusive concept. Cities, 12(5), 353-359. https://doi.org/10.1016/0264-2751(95)00069-X

Wilheim, J. (2013). Mobilidade urbana: um desafio paulistano. Estudos Avançados, 27(79), 7-26. http://dx.doi.org/10.1590/S0103-40142013000300002 